\title{
Hubungan Agama dan Sains: Telaah Kritis Sejarah Filsafat Sains Islam dan Modern
}

\author{
Nur Hadi Ihsan ${ }^{1 *}$, Khasib Amrullah ${ }^{2}$, Usmanul Khakim $^{3}$, Hadi Fatkhurrizka ${ }^{4}$ \\ 1,2,3,4 Universitas Darussalam Gontor Ponorogo, Indonesia
}

\begin{abstract}
Abstrak: Penelitian ini bertujuan untuk mendeskripsikan hubungan agama dan sains dari perspektif sejarah filsafat sains Islam dan sains Barat modern. Kajian ini merupakan kajian pustaka dengan data kualitatif. Pendekatan yang digunakan adalah pendekatan sejarah (historical approach) dalam hal ini sejarah filsafat sains Barat dan Islam. Data akan dianalisis menggunakan analisis konten. Penelitian ini menemukan bahwa pertama, dalam sejarahnya, sains Islam dibangun berdasarkan wahyu yang dikonfirmasi dengan akal dan observasi, sementara dalam sejarah kebudayaan Barat, lahirnya sains modern berpaku pada gerakan sekularisasi; yang mengafirmasi kebenaran rasio dan pengalaman indrawi di satu sisi dan menolak kebenaran doktrin agama (Gereja) di sisi yang lain. Kedua, setelah sains Islam mengalami kemunduran, sains modernlah yang menjadi kiblat dan mendominasi sains dunia. Dan ketiga, respon ilmuwan Muslim terhadap dominasi sains modern adalah dengan gerakan Islamisasi ilmu pengetahuan; secara khusus dengan melaksanakan program riset sains Islam.
\end{abstract}

Kata Kunci: Sains Islam, Sains Modern, Islamisasi, Sekularisasi

\begin{abstract}
This study aims to describe the relationship between religion and science from the historical perspective of Islamic philosophy of science and modern Western science. This study is a literature review with qualitative data. The approach used is a historical approach, in this case the history of Western and Islamic philosophy of science. The data will be analyzed using content analysis. This study finds that first, in its history, Islamic science was built based on revelations confirmed by reason and observation, while in the history of Western culture, the birth of modern science was based on the secularization movement; which affirms the truth of reason and sensory experience on the one hand and rejects the truth of religious doctrine (the Church) on the other. Second, after Islamic science experienced a decline, modern science became the mecca and dominated world science. And third, the response of Muslim scientists to the domination of modern science is the Islamization of science; specifically by carrying out Islamic science research programs.
\end{abstract}

Keywords: Islamic Science, Modern Science, Islamization, Secularization

\section{Pendahuluan}

Hubungan antara agama dan sains merupakan merupakan diskursus yang selalu menarik didiskusikan, khususnya sejak muncul gerakan sekularisasi di dunia Barat. Sejarah hubungan sains dan agama di Barat mulai popular sejak digaungkannya teori Heliosentris oleh Galileo Galilei (w.1642) (Barbour, 2000). Gereja terkejut selaku pemegang otoritas kebenaran mendapat hantaman dari para ilmuwan; utamanya kebenaran sains yang berlawanan dengan doktrin Gereja

\footnotetext{
* Corresponding Author: Usmanul Khakim (usmanulhakim680@unida.gontor.ac.id). Universitas Darussalam Gontor Ponorogo, Indonesia
}

p-ISSN 1412-1697; e-ISSN 2477-3816

http://jurnal.radenfatah.ac.id/index.php/intizar 
(Barbour, 2002). Peristiwa ini menjadi pintu gerbang terjadinya sekularisasi di Barat. Semakin menjadi, pasca Galileo, Isaac Newton (w.1727) dan tokoh-tokoh ilmuwan sekuler lainnya menolak intervensi Tuhan dalam sains (Azizah, 2018). Pada akhirnya, Tuhan laksana pembuat jam dalam benak para ilmuwan itu. Pada kondisi semacam ini Gereja secara berangsur ikut hanyut dalam alur sekularisasi (Al-Attas, 1993). Hal berbeda terjadi pada sejarah sains Islam yang telah lebih dahulu mengalami kemajuan; dimana seorang saintis tidak memiliki masalah dengan agamanya (Azizah, 2018). Di sini dapat diketahui bahwa secara umum kebudayaan Barat yang mengalami proses sekularisasi memisahkan dengan tegas sains dengan agama.

Hubungan yang demikian tidak serta-merta selalu diamini oleh ilmuwan Barat sendiri. Pada era-90-an ramai dibicarakan tema mengenai hubungan agama dan sains. Nama yang popular diantaranya Ian G Barbour, Nacey Murphy, Philip Hefner, Arthur Peachok, John F Haught, (Arifin, 2008). Pemisahan agama dan sains secara tegas membawa masalah yang serius dimana nilai moralitas sakralitas dan kebijaksanaan tidak lagi berurusan dengan sains (Ma'afi \& Cholidi, 2019). Oleh karena itu sebagaimana diungkapkan oleh Taqiyuddin bahwa dalam kondisi yang demikian alternatif integrasi selalu diidealkan pada hubungan agama dan sains (Taqiyuddin, 2021).

Dalam perkembangannya, diskursus ini juga menjadi materi diskusi yang menarik bagi para sarjana Muslim hari ini. Secara nyata dapat dilihat dari banyaknya kajian yang telah membahas tema ini. Di antara kajian yang relevan adalah yang ditulis oleh Zainul Arifin (2008); yang menyoroti berbagai model hubungan agama dan sains yang dikemukakan oleh sarjana Barat melalalui pendekatan ontologis, epistemologis dan aksiologis. Kajian ini mendatangkan kesimpulan bahwa secara filosofis agama dan sains memang merupakan entitas yang berbeda, namun konsolidasi keduanya perlu dilakukan agar tidak menjadi sumber konflik kehidupan manusia. Kesimpulan senada juga diutarakan oleh Zaprulkhan (2017). Meskipun kajian keduanya menghasilkan kesimpulan yang identik, namun kedua kajian memiliki pendekatan yang berbeda. Jika Zainul Arifin menggunakan pendekatan filsafat, Zaprulkhan memilih pendekatan metodis penelitian sains dan agama (Zaprulkhan, 2017). Kajian yang lain dilakukan oleh Syarif Hidayatullah (2019). Secara tegas ia menyebut bahwa objek formal kajiannya adalah filsafat ilmu. Meskipun begitu kesimpulan yang dihasilkan sama dengan 2 kajian sebelumnya.

Kajian-kajian selanjutnya banyak dilakukan dengan mengelaborasi pemikiran seorang tokoh secara spesifik tentang hubungan sains dan agama; atau dalam bentuk perbandingan. Sebagai contoh, Taqiyuddin mengkaji pemikiraan al Attas (2021), Nur Azizah (2018) mengkaji Kuntowijoyo yang sebelumnya telah dibahas pula oleh Muh Tasrif (2008). Sementara itu, Mas'udi (2013) menampilkan perbandingan antara al Ghazali dan Ibn Rusyd dalam hubungan sains dan agama. Selanjutnya, Sholeh (2017) melakukan perbandingan antara pemikiran al Attas dan Faruqi, sama dengan kajian Irma Suryani (2018). Lain halnya, Wedra Aprison (2015) menelaah pemikiran Harun Nasution. Dari berbagai kajian di atas, dapat diketahui bahwa diskursus hubungan antara agama dan sains semakin diminati dan penting.

Sebagaimana kajian yang telah disebutkan di atas, dan sebagai pelengkap atas kajian-kajian tersebut, maka, artikel ini akan mengambil posisi yang berbeda. Kajian ini akan mengelaborasi hubungan antara agama dan sains dari pendekatan sejarah; dalam hal ini sejarah filsafat sains Islam dan Barat. Kajian ini akan menyoroti sejarah lahir 
dan perkembangan sains Islam, sejarah lahir dan perkembangan sains modern, dan respon ilmuwan Muslim dalam menghadapi dominasi sains Modern.

\section{Metode}

Kajian ini merupakan kajian pustaka (Tavakoli, 2012); dengan data kualitatif (Sugiyono, 2011). Data akan didapat dari berbagai buku atau sumber tertulis lainya sebagai sumber primer dan sekunder. Di antara sumber utama kajian ini adalah Islamic Science Toward a Definition (2016) karya Alparslan Acikgenc, Islamic Science: paradigma, Fakta dan Agenda (2016) oleh Hamid Fahmy Zarkasyi et.al, Islamic and aArab Contribution to the European Renaissance (1977) oleh Komisi Nasional UNESCO dan Filsafat Ilmu Perspektif Barat dan Islam (2013) oleh Adian Husaini et.al., dan Filsafat Ilmu (2016) oleh Mohammad Muslih. Data akan dianalisis menggunakan analisis konten (content analysis) yakni penulis melakukan interpretasi kritis terhadap data tertulis yang didapatkan (Krippendoff, 2004). Selain itu, juga akan dilakukan analisis perbandingan atas argumentasi-argumentasi pada tema terkait. Pendekatan yang digunakan adalah pendekatan sejarah dalam hal ini sejarah filsafat sains Barat dan Islam.

\section{Hasil dan Pembahasan}

\section{Definisi Agama}

Secara etimologi, agama berasal dari bahasa Sansekerta " $a$ " yang artinya tidak dan "gama" yang berarti rusak atau kacau. Karenanya, agama berarti tidak rusak dan kacau. Sehingga agama mempunyai makna yang mempuyai pengikut jauh dari kekacauan dan kerusakan (Ismail, 1997).

Adapun dalam bahasa Inggris, lafal agama adalah terjemahan harfiah dari "religion" yang Intizar - Vol. 27 No. 2 (2021) diartikan a strong belief in a supranatural power or powers that control human destiny, keyakinan yang kuat akan kekuatan supranatual yang dapat mengontrol tujuan (nasib) manusia (Crowther, 2010). An institution to express belief in a devine power institisi yang mengekspresikan kekuatan keyakinan tentang ketuhanan (Crowther, 2010). Di dalam Cambridge Advanced Learner's Dictionary, religion diterjemahkan sebagai, the belief in and worship of a god or gods; or any such system of belief and worship. ...... an activity which someone is extremely enthusiastic about and does regularly, football is religion for these people (Cambridge University, 2008). Artinya (agama) adalah 1) keyakinan dan penyembahan kepada tuhan baik satu ataupun banyak; atau 2) sebagai sebuah system keyakinan dan penyembahan; 3) perilaku reguler manusia berdasarkan antusiasme yang ekstrim, (sebagai contoh) sepakbola merupakan agama bagi mereka. Kemudian definisi 'religion' yang diberikan Oxford Advanced Learner's Dictionary tidak jauh beda dengan definisi yang diberikan Cambridge Advanced Learner's Dictionary. Hanya saja, definis dari Oxford menambahkan satu hal yaitu; one of the system of faith that are based on the belief in the existence of pertcular God or gods (the Jewish religion, Christianity, Islam and other world religions the law states that everyones has the right to practice their own religion (Crowther, 2010). Intinya, agama adalah salah satu sistem kepercayaan (keimanan) berdasarkan keyakinan terhadap eksistensi atau sifat-sifat khas Tuhan atau Tuhan-tuhan. Pengertian lain seperti tertulis dalam Encyclopedia of World Religions, bahwa religion in all its forms, implies a relationship between human beings and super human powers which are believed to affect human affairs (Team, 1975). Agama dalam segala bentuknya mengandung makna hubungan antara manusia dan kekuatan 
supra-natural yang diyakini mempengaruhi urusan manusia.

Selanjutnya akan dikemukakan definisi agama dalam bahasa Arab. Agama diterjemahkan dari kata "al-dîn" akar kata darinya adalah dana yang memiliki beberapa arti, "danatu" bermakna "malakahu" (memilikinya), "wahakamahu" (berkuasa atasnya), "wasasahu” (mengaturnya), "wa dabbarahu" (mengoordinasikannya), "wa qawarahu" (memaksanya), "wa hasabahu” (menghitungnya), "wa qada fi sya'nihi" (memutusnkan dalam urusannya), "wajazahu" (memberinya imbalan), "wa kafa'ahu" (memberi apresiasi) (M. K. Muslih, 2018).

Ibnu Manzur dalam kamus Lisân al'Arab memaknai kata "dîn" dalam empat bagian. Pertama, bermakna hukum, kuasa, tunduk, mengatur, dan perhitungan (al-hukm wa siyâsat alumûr wa al-qahr wa al-tadbîr wa al-muhâzasah). Kedua, dîn berarti ketertundukan, taat, pengabdian, tunduk (al-taskîrr, wa al-taskhîr, wa al-itâ 'at wa alkhudû). Ketiga, dîn bermakna pembalasan, perhitungan, dan ganjaran (al-jazâ' 'wa al-hisâb wa al-mukafâ'ah). Keempat, dîn bermakna akidah (alI'tiqâd). Dîn dalam pandangan ini adalah jalan atau syarat yang dilaksanakan oleh seseorang (Manzur, n.d.). Jika ditelaah, dalam istilah dîn tersembunyi suatu sistem kehidupan yang teratur berdasarkan hukum dan keadilan. Karenanya, ketika dîn (agama) Allah yang dimaksud di sini bernama Islam artinya telah disempurnakan dan dilaksanakan di suatu tempat, yang disebut Madinah (Fahmy Zarkasyi, 2015). Dari akar kata Dîn dan madînah ini lalu terbentuk akar kata baru madana yang berarti membangun, mendirikan kota, memajukan, memurnikan, dan memartabatkan (H. F. Zarkasyi, 2015).

Dengan demikian, definisi agama secara terminologi adalah institusi yang mengajarkan tentang keyakinan terhadap keberadaan suatu yang metafisik, dimana Tuhan menempati kedudukan tertinggi dalam keyakinan itu. Tuhan yang mengatur sistem kehidupan berdasarkan hukum dan keadilan. Intinya secara epistemologis, agama menerima eksistensi fisik dan metafisik dinama Tuhan sebagai eksisitensi non-fisik tertinggi; yang merupakan eksistensi mutlak, yang menguasai segala eksistensi.

\section{Definisi Sains}

Selanjutnya, akan dijelaskan definisi dari sains. Secara etimologi, kata 'sains' dalam bahasa Indonesia diadaptasi dari kata dalam bahasa Inggris "science" yang sebenarnya berasal dari bahasa Latin "scientia" yang berarti mengetahui atau pengetahuan, (to know, knowledge) dan perkataan Latin juga 'scire' yang berarti belajar (to learn) (M. Muslih, 2016). Dua istilah tersebut identik dengan istilah Arab, 'alima, 'ilm yang dalam tradisi Islam masih dibedakan dengan istilah idrak (persepsi) yang bertumpu pada pencerapan indrawi dan irfan (pengenalan) (M. Muslih, 2017).

Jujun S. Suriasumantri (2007) memberikan penjelasan dengan memisahkan kata knowledge dan sains. Yang pertama adalah knowledge diartikan menjadi "Ilmu" dan science menjadi 'Ilmu pengetahuan'. Secara semantik knowledge memang lebih tepat diterjemahkan menjadi "Ilmu" apalagi jika dilihat kata ini diturunkan dari 'ilm yang sebagi istilah generik (umum) dalam bahasa Arab, agak memiliki nuansa yang sama dengan knowledge; sedangkan science merupakan spesies ilmu, mesti diterjemahkan menjadi "Ilmu pengetahuan" karena pengetahuan memang merupakan semacam spesies dari ilmu (Syed Muhamed Naquib Al-Attas, 1995; S. Hadi \& Ashari, 2020).

Terlepas dari perbedaan akar kata sains, namun sains telah memperoleh beragam definisi 
yang mengacu pada istilah penggunaanya. Sains (science) secara istlah didefinisikan "knowledge from the systematic study of the structure and behaviour of the physical world, especially by watching, measuring and doing experiments, and the development of theories to describe the results of these activities (Drapper, 1875)

Dengan demikian definisi sains secara terminologi merupakan pengetahuan (knowledge) yang mempunyai sangkut paut dengan fenomena fisik dengan pendekatan percobaan, pengalaman, pengembangan teori yang mampu membentuk sistem berpikir secara rasional. Definisi di atas mengacu pada beberapa hal menarik yaitu: Pertama sains hanya terkait dengan objek fisik pengetahuan. Kedua, sains hanya mengakomodir 2 sumber ilmu yakni rasio dan pengalaman indrawi. Inilah pengertian sains menurut kebudayaan Barat sekuler.

Sebetulnya sains Islam tidak sepenuhnya menafikan definisi sains Barat di atas. Sains Islam juga mengakomodir dunia indrawi sebagai objek sains dan rasio serta indera sebagai sarana sains, namun sains Islam menerima wahyu sebagai sumber kebenaran (Khakim et al., 2020); yang mempunyai tujuan untuk melakukan tata nilai ilmu dan tata nilai adab Islami dalam semua kegiatan sains dan teknologi (H. F. Zarkasyi et al., 2016). Dengan begitu, agama (wahyu) yang tidak bersumber dari rasio dan pengalaman indrawi mendapat tempatnya dalam sains Islam.

\section{Sejarah Lahir dan Kemajuan Sains Islam}

Sains Islam yang lahir dari sebab turunnya wahyu ilahi (al-Qur'an) kepada Nabi Muhammad Saw kemudian disebarkan dan dipahami oleh akal dan intuisi manusia (H. F. Zarkasyi, 2015). Sebagai sebuah ajaran sekaligus agama yang bersifat universal (Al-Kathany, 1995; Aprison, 2015);
Islam telah memberikan sumbangsih besar terhadap peradaban dunia dan kemajuan manusia. Hamid Fahmy (2016) menyebut 4 fase kelahiran tradisi ilmiah dalam Islam; yakni periode nubuwah, pembentukan strukutur ilmu al Qur'an dan hadis, lahirnya tradisi kelimuan dan lahirnya disiplin ilmu Islam.

Fase pertama adalah masa turunnya wahyu. Alparslan Acikgenc menjelaskan bahwa periode ini terjadi pada saat Nabi Muhammad Saw masih hidup, yaitu pada 2 periode Makkah dan Madinah (Acikgenc, 1996). Pada fase ini Nabi meletakkan dan mengatur sistem keyakinan fundamental umat Islam; artinya pembentukan pandangan dunia Islam (Islamic worldview) (Husaini et al., 2013). Worldview inilah yang akan menjadi basis dibangunnya tradisi ilmiah dalam Islam.

Fase Kedua, munculnya struktur ilmu pengetahuan al-Qur'an dan Hadits. Fase ini ditandai dengan kesadaran akan perlunya menjelaskan konsep-konsep fundamental yang terkandung pada al-Quran dan Hadis; seperti kosep tentang iman, Islam, ihsan, wujud, akhirat, dan lain-lain (H. F. Zarkasyi et al., 2016). Konsep-konsep itu dianggap sebagai kerangka awal konsep keilmuan.

Fase Ketiga lahirnya tradisi keilmuan Islam. Sebagai konsekuensi logis dari adanya kerangka awal konsep keilmuwan Islam, dan ditambah lagi dengan adanya perkembangan masalah yang dihadapi umat Islam. Fase ini ditandai dengan adanya hadirnya komunitas ilmiah; yang masyhur adalah para ashab suffah (Acikgenc, 1996). Di tangan komunitas ilmiah semacam ashab suffah seperti Abu Hurairah, Abu Dzar al Ghifari, Salman al Farisi pada generasi awal dan Qadi Syuraih (w.699) Muhammad ibn al-Hanafiyah (w.700), Umar Ibn Abdul Aziz (w.720) Hasan al Bashri (w.728) pada generasi selanjutnya (Husaini et al., 2013)-inilah tradisi ilmiah mulai terlihat, meskipun 
belum menghasilkan perumusan ilmu secara spesifik dalam berbagai disiplinnya.

Fase keempat adalah fase lahirnya disiplin ilmu-ilmu Islam. Pada fase ini komunitas ilmiah mulai melakukan spesifikasi terhadap berbagai jenis disiplin ilmu; membedakan satu disiplin ilmu dengan yang lain; memberi nama yang spesifik (Acikgenc, 1996). Seperti ilmu fikih, ilmu nahwu, ilmu sharf; dan dalam perkembangannya selanjutnya menyentuh disiplin sains, seperti ilmu astronomi, ilmu pertanian, ilmu kenegaraan, dan sebagainya.

Keempat fase tersebut terbangun sejak 750 M sampai mencapai puncak kejayaannya sekitar tahun $1258 \mathrm{M}$; telah menghasilkan banyak kontribusi terhadap perkembangan teknologi dan kebudayaan, baik dengan menjaga tradisi yang telah ada ataupun dengan menambahkan penemuan dan inovasi ilmuwan Muslim sendiri (Gunawan, 2019). Berjilid-jilid buku ditulis sebagai hasil dari kajian tentang disiplin ilmu yang digeluti. Dalam bidang astronomi misalnya Ma'rifat Mațāli $i l$ Burūj karya al Battani (Ilafi, 2021b), dalam bidang kedokteran Al-Tasrif karya Abul Qasim al-Zahrawi (Ilafi, 2021a); dalam bidang filsafat terdapat Asyyifa' al Ilahiyat karya Ibn Sina (Attar, 2015); dalam bidang pertanian ada buku al Filahah karya Ibn Awwam (Khuluq \& Syamsuri, 2020) dan sebagainya; yang semuanya telah diwariskan bagi kemaslahatan hidup manusia.

Kegemilangan itu tidak lantas menjadikan para ilmuwan Muslim meninggalkan agama. Mereka memandang sains dan agama adalah hal yang tidak ada pertentangan. Mempelajari sains bagi meraka juga merupakan kewajiban beragama (ibadah). Sains bagi ilmuwan Muslim adalah sebagai ajang pembuktian rasional, nalar, dan logika ilmu pengetahuan yang berbasis wahyu (alQur'an dan Hadis). Hal ini mempertegas bahwa sains atau ilmu pengetahuan dalam Islam tidak mungkin akan dipertentangkan satu sama lain.

Hal yang menyebabkan ilmuwan Muslim tidak mempertentangkan agama dan sains adalah kesatupaduan pemikiran atau kerangka berfikir yang didasarkan atas cara pandang terhadap dunia atau yang dikenal dengan basis (Islamic worldview). Bagi ilmuwan Muslim sains dan agama adalah bersumber dari sumber yang sama, jadi sama-sama valid dan dapat diterima.

Satu metode yang dipegang, jika dirasa ditemukan pertentangan antara sains dan agama adalah dengan menyelaraskan atau mencocokkan bacaan keduanya. Bagi ilmuwan muslim akal dan wahyu sama-sama digunakan sesuai tempatnya yang adil (I. Zarkasyi, 1986). Jika saja wahyu dirasa bertentangan dengan akal, maka kontradiksi tersebut dipandang bukanlah sebagai proses akhir (ultimate)(F. S. Hadi, 2019). Artinya pendekatan yang digunakan adalah agar pemahaman tentang wahyu diperdalam dan pengetahuan rasional diteliti lebih jelas lagi. Sebab, boleh jadi pembacaan manusia atas wahyu dan rasional akalnya kurang teliti dan bisa saja luput dari pemahaman dan tafsir yang benar atasnya. Saintis Muslim adalah manusia rasional karena menggunakan dua sumber kebenaran, wahyu dan akal secara adil (Al-Faruqi, 1980, p. 47). Artinya, wahyu tetap berposisi menjadi kebenaran mutlak yang diterima seluruh ilmuwan Muslim; sisi yang dikoreksi hanya pada tataran pembacaan manusia atasnya.

Hal ini menunjukkan bahwa di dalam sains Islam, al-Qur'an adalah sumber utama ilmu pengetahuan. Seperti yang disampaikan Syekh Yusuf Qardawi, al-Qur'an merupakan kitab suci umat Islam di dalamnya bersumber segala macam ilmu pengetahuan (Qardawi, 1997). Al-Qur'an sebagai sumber ilmu pengetahuan bermakna bahwa kebenaran al-Qur'an adalah sebagai kebenaran 
mutlak ilmu (Sholeh, 2017). Sains kemudian dikembangkan berasaskan pada kebenaran objektif wahyu.

Dengan begitu, sains dan agama adalah satu kesatuan. Tidak ada dikotomi antara keduanya (Wahyuni, 2018). Agama yang berunsurkan keyakinan metafisika tetap memiliki pengaruh yang besar pada penelitian ilmiah (scientific reasherch). Berbagai keyakinan fundamental dalam aktifitas sains yang meliputi paradigma, asumsi dasar dan bahkan hipotesis penelitian -yang sebenarnya diakui oleh sebagian ilmuwan modern- sejatinya adalah hal-hal yang metafisk; bisa saja bersumber dari ajaran agama. Artinya, disingkirkannya agama dari sains adalah tidak mendasar karena bertentangan dengan nalar, logika dan realita (M. K. Muslih, 2018). Begitulah cara pandang Islam.

Dalam sains Islam, wahyu mendapat tempat tertinggi dan utama. Posisi agama sangat sentral, penting bahkan sains digali dari wahyu yang notabennya adalah sumber kebenaran; termasuk kebenaran sains (Khakim et al., 2021). Di sini terlihat begitu sentralnya wahyu dalam sains Islam.

\section{Wahyu dan Pengembangan Sains Islam}

Telah disepakati oleh kaum Muslimin bahwa mukjizat Islam yang paling utama ialah al-Qur'an yang mempunyai nilai inheren dengan ilmu pengetahuan. Allah adalah sumber segala ilmu pengetahuan (Siregar \& Siregar, 2018). Bahkan surah pertama yang diwahyukan Allah kepada Nabi Muhammad ialah tentang ilmu pengetahuan (Q.S Al-Alaq: 1-5). Tidak ada di kalangan ulama manapun yang menentang al-Qur'an yang di dalam teks-teksnya mengandung simbol-simbol ilmu pengetahuan. Terdapat kurang lebih 750 rujukan yang berkaitan dengan ilmu pengetahuan (Nordin, 2000).

Intizar - Vol. 27 No. 2 (2021)
Hamid Fahmy Zarkasy (2016) mengamini pendapat mengenai al-Qur'an sebagai sumber kebenaran sains. Ia berpandangan bahwa tradisi keilmuan lahir justru karena kandungan yang terdapat dalam al-Qur'an dan memberi stimulus para sahabat Nabi untuk berpikir. Sebut saja Jabir Ibnu Hayyan al-Kufi (721-813M). Ilmuwan yang berasal dari Kufah itu, yang dikenal sebagai alkemi (ilmu kimia), hasil dari kajiannya hampir menjadi satu ensiklopedi sains dan memberi ringkasan ilmu kimia pada masa itu. Jabir telah memperkenalkan manfaat praktis kimia untuk membersihkan besi dari larutan, mencelup kain dan kulit, menggunakan minyak varnis untuk zat anti air bagi kain, penggunaan karbon dioksida untuk mewarnai gelas serta penyulingan cuka menjadi asam asetat yang pekat (Khan, 1973). Temuan ini tentu didorong atas perintah wahyu untuk memikirkan alam semesta.

Sebagaimana diketahui, ilmu kimia adalah satu disiplin ilmu yang tidak ditemukan sebelum datangnya Islam. Menurut catatan Sulaiman Nordin bangsa Yunani telah mengetahui beberapa bahanbahan kimiawi tetapi tidak mengetahui unsurunsurnya secara spesifik seperti asam sulfat (H2SO4), asam nitrat (HNO), raksa klorida (HgC12) (Nordin, 2000). Selanjutnya, penyediaan raksa telah dilaporkan untuk pertama kalinya oleh ahli-ahli kimiawan Muslim (Nordin, 2000). Lain daripada itu, seorang sarjana Amerika Haider Bammate (1962) pernah berkata:

"Proses mendasar dalam kimia yaitu penyulingan merupakan suatu penemuan umat Islam dan merekalah yang pertama kali menggunakannya. Karena itu, kita harus memberi pengakuan bahwa sumbangan umat Islam kepada sains benar-benar tidak diragukan lagi"

Adapun ilmuwan Muslim lain Muhammad Abu Bakar al-Razi (865-925M) yang lebih populer dengan sebutan al-Razi yang terkenal dengan 
kedokteran kimia. Al-Razi adalah perintis kimia modern. Ia menciptakan peralatan dan mencatat secara rinci lebih dari dua puluh alat besi dan kaca untuk penelitian di laboratoriumnya. Ia mengatakan bahwa keseimbangan dari penyakit adalah karena reaksi kimia yang terdapat di dalam tubuh atau badan (National Commission for UNESCO, 1977, p. 191). Al-Razi membagi bahan kimia menjadi jenis-jenis yang lebih kecil (National Commission for UNESCO, 1977). Logam dibagi menjadi jiwa, tubuh, batu, vitriol, borax dan garam. Benda yang mudah menguap dipisahkan dari yang tidak menguap (Hoesin, 1964).

Terdapat banyak bukti bahwa saintis Muslim telah memberikan sumbangsih besar terhadap peradaban sains Modern. Bukan hanya pengakuan oleh Muslim, akan tetapi tokoh dan ilmuwan Barat non-Muslim pun mengakui akan superioritas para saintis Muslim. Dalam pengantar buku 1001 Inventions Muslim Heritage in Our World disebutkan;

"...If there is much misunderstanding in the West about the nature of Islam, there is also much ignorance about the debt our ouw culture and civilization owe to the Islamic world. It is a failure, which stems, I think, from the straight-jacket of history, which we have inherit. The nedieval Islam world, from centrak Asia to the shore of Atlantic, was a world where scjolars and men pf learning flourished. But because we have tended to see Islam as the enemy of the west. as an alience culture, society, and system of belief, we have tended to ignore or erase its great relevance to our own history..." (Abattouy et al., 2005).

Ungkapan tersebut adalah sebuah pengakuan atas jasa sains Islam kepada Barat. Kemudian masih dalam buku yang sama, sejarawan perempuan kepala eksekutif Hewlett-Packard Corporation,
Carleton Florida pada September 2001 pada pidatonya mengatakan;

"There was once a civilization that was greatest in the world. It was able to create a continental super-state that stretched from ocean to ocean and from northern climes to tropics and deserts. Within its dominion lived hundrends of million of people, of different creeds and ethnic origin... when cencors threatened to wipe out knowledge from the past cibilizations, this civilization kept the knowledge alive, and passed it on to others. The civilization I'am talking about was the Islamic world from the year 800 to 1600 , which included the Ottoman Empire and the courth of Baghdad, Damascuss and Cairo"(Abattouy et al., 2005).

Tentunya, tanggapan Florida di atas objektif. Secara defacto dan dejure peradaban dan kemajuan sains Islam mampu bertahan kurang lebih 8 abad. Jika tidak mengakuinya, berarti buta sejarah, miskin pengetahuan dan peradaban. Pengakuan yang Florida sampaikan memberikan penegasan kepada saintis Modern yang dengan kemajuan ilmu dan teknologinya belum mampu menyaingi kegemilangan peradaban sains Islam ketika jayanya. Kejayaan tersebut tidak lain dari jihad para ilmuwan Muslim menjaga kecerdasan intelektual dan spiritual mereka. Kecerdasan intelektual Muslim khususnya dalam bidang sains saat itu, sejalan dengan ketaatan mereka kepada Allah. Tidak lantas meninggalkan amal ritual dan spiritual. Saintis Muslim di zaman kejayaan Islam adalah mereka yang manjaga Islam dengan iman, ilmu dan amal mereka. Inilah kunci kesuksesan peradaban sains Islam

\section{Sejarah Lahir Sains Barat}

Memasuki abad ke-18 perkembangan sains dan teknologi berpindah kiblat. Berakhirnya dinasti Turki Utsmani pada tahun 1924 M, menandakan 
kebekuan sains, ekonomi dan politik Islam (Akhyar, 2017). Sementara itu di dunia Barat, kemajuan ilmu pengetahuan demikian pesat ditandai dengan kemunculan revolusi industri yang dimotori dengan gerakan renaissance yang muncul kira-kira pada abad ke-14 sampai dengan abad ke17 (Jessie, 2016).

Sains Barat-sekuler merupakan gagasan yang dibawa Barat dari arus sekularisasi yang terjadi sejak masa renaisannce hingga kini. Arus sekularisasi -yang datang tepat disaat masyarakat Barat mengalami trauma terhadap Gereja- telah membawa masyarakat Barat secara berangsurangsur melepaskan diri dari otoritas Gereja (Nugroho, 2018). Hal inilah yang menjadi pemicu penolakan agama dalam sains; agama memiliki kebenarannya sendiri dan sains juga memiliki kebenaran yang bebas dari agama. Agama dipandang tidak bisa masuk ke dalam sains karena tidak empiris dan rasional. Artinya, sains modern hanya mengutamakan rasionalitas dan bukti empiris; bahkan konsep agama harus direduksi ke dalam struktur penalaran rasio dan empiris. Seperti kata "Tuhan" bukan dimaknai sebagai sebuah Supra-Eksistensi Mutlak, namun dimaknai sebagai kebaikan, sedangkan "setan" adalah keburukan, "syurga" adalah kesenangan dan "neraka" adalah kesusahan (Khakim et al., 2020).

Ian Barbur (2000) seorang ilmuwan sekaligus teolog Barat menuliskan sejarah terbentuknya sains Barat yang sekuler. Ia mengangkat sebuah fakta tentang perseteruan antara Galileo dan gereja. Kasus yang terjadi pada Galileo tahun 1633M merupakan pos-kontras konflik serius antara saintis dengan pemegang otoritas Gereja. Akibat dari pertentangan ini, ilmuwan Galileo harus rela diakuisisi oleh Gereja karena mendukung teori Copernicus yang mengajukan teori heliosentris; yang mengungkap bumi dan planet-planet mengelilingi matarhari. Sementara, Gereja Katolik tetap pada pendirian atas dokrin Aristoteles mengaggap matahari mengelilingi bumi (Barbour, 2000).

Sebagai gerbang pembuka, menurut Barbour (Barbour, 2002), Galileo bukanlah orang pertama yang menyuarakan perlawanan terhadap teks-teks kitab suci Kristen. Sebelum Galileo, Agustine adalah saintis pertama, ia sebagai pioner yang mengkritisi teks-teks Gereja. Ia menjadi pra-kontras pertentangan awal saintis dengan pemegang otoritas Gereja. Konflik pra dan post-kontras Agustine dan Galileo inilah yang disebut sebagai hubungan pertama 'konflik' antara sains dan agama (Drapper, 1875). Apa yang terjadi tersebut menyebabkan lahirnya cara pandang sekuler.

Berpijak pada cara pendang sekuler, dalam sejarah keilmuan Barat dapat ditemukan berbagai aliran kefilsafatan yang membangun paradigma keilmuan Barat-sekuler. Partama, rasionalisme. Aliran ini dianggap sebagai aliran yang pertama kali muncul dalam teori pengetahun modern. Di antara tokoh utama aliran ini adalah Rene Descartes (1596-1650M), Baruch Spinoza (1632-1677M), Gottfried Leibniz (1646-1716M). Nama pertama adalah yang paling berpengaruh yang mendapat gelar "Bapak filsafat Modern" menformulasikan sebuah prinsip, "cogito ergo sum" aku berfikir, maka aku ada (M. Muslih, 2016). Maka secara ringkas aliran ini mengunggulkan rasio sebagai satu-satunya sumber kebenaran pada pengetahuan. Al Attas mengakui bahwa pengaruh sekularisasi terhadap ilmu diawali oleh revolusi Cartesian ini (Syed Muhamed Naquib Al-Attas, 1993). Kedua, empirisisme. Di antara tokoh utama aliran ini John Locke (1632-1704M), George Berkeley (16851753M) dan David Hume (1711-1776M) (M. Muslih, 2016). Aliran ini muncul dengan membantah ide aliran rasionalisme. Bagi aliran ini 
bukan rasio, namun pengalamanlah yang merupakan satu-satunya sumber pengetahuan. Ketiga, Kritisisme. Tokoh utama aliran ini adalah Immanuel Kant (1724-1804M). Ia mencoba mendamaikan kedua aliran sebelumnya (Sitorus, 2016).

Dari ketiga aliran inilah nantinya akan melahirkan berbagai aliran-aliran paradigmatik keilmuan Barat sekuler seperti; positivisme, postpositivisme, konstruksivisme, dan critical theory (M. Muslih, 2016). Dari paradigma itu akan muncul metode-metode ilmu seperti induksi-eksperimen oleh Francis Bacon, Logika Induksi oleh John Stuart Mill, positif-empiris oleh Auguste Comte, Verifikasi dan konfirmasi oleh Lingkaran Wina, Falsifikasi oleh Karl Popper (M. Muslih, 2016).

Jika dilihat dari kacamata filsafat ilmu (epistemologi) bahwa apa yang telah dipaparkan di atas merupakan struktur keilmuan Barat moden. Dalam ulasan itu tidak jarang terjadi perbedaan bahkan bertolak belakang antara satu aliran dengan yang lain. Meskipun begitu, nampak bahwa aliranaliran itu berawal dari cara pandang yang sama yakni worldview sekuler; mereka sepakat menolak agama dalam struktur bangunan ilmunya. Bagi alAttas berbagai aliran paradigmatik keilmuan Barat sekuler bermula pada rasionalisme dan empirisisme (Syed Muhamed Naquib Al-Attas, 1995). Karena hanya rasio dan pengalaman indrawi saja yang menjadi sumber ilmu sekaligus justifikator kebenaran atasnya, maka ilmu pengetahun sekuler sebenarnya berpijak pada kebenaran yang tidak tetap; ia bertolak pada keterbatasan rasio dan indera yang mendorong pada keragu-raguan. Ilustrasinya, yang saat ini benar besok bisa salah, yang di sini benar di sana bisa salah, yang menurutku benar menurutmu bisa salah. Akibatnya skeptisisme diangkat ke dalam struktur epistemologis.
Seperti diketahui, zaman renaissance adalah zaman yang didukung oleh cita-cita untuk melahirkan kembali manusia yang bebas yang tidak terbelenggu oleh dogma gereja atau agama (Asy'ari, 2018). Manusia yang bebas ala renaissance merupakan manusia yang tidak terikat oleh otoritas tradisi, sistem gereja, dan sebaginya, kecuali otoritas yang ada pada masing-masing diri pribadi, kemudian atas sikap tersebut melahirkan sikap mental manusia yang percaya akan kemampuan diri sendiri atas dasar rasionalitas dan sangat optimis untuk menguasai masa depannya. Perkembangan dan dasar mental kebebasan tersebut juga akhirnya mempengaruhi perkembangan sains dan teknologi Barat dan membentuk paradigma untuk menguasai alam. Semenjak saat itu, Barat telah tinggal landas melakukan lompatan kemajuan sains dan teknologi (Nugraha, 2020); mengarungi cakrawala sains yang tiada bertepi; menguasai peradaban dunia termasuk dunia Islam (Salafuddin, 2013). Tujuannya hanya satu, yaitu menaklukkan dan menguasai alam demi kepentingan 'kesejahteraan hidup sekuler mereka' (Sutoyo, 2010). Selain itu gerakan kolonialime Barat ke dunia Islam juga ikut mendorong adanya dominasi sains modern ke seluruh penjuru dunia utamanya dunia Islam.

Taqiyuddin (2021) menyatakan bahwa negara-negara yang saat ini sangat berkontribusi dalam sains dan teknologi mayoritas merupakan negara-negara Barat.Tidak dinafikan kemajuan sains Barat yang begitu dahsyat memberikan pemahaman tentang ketertinggalan Islam dan dominasi Barat. Menyadari hal ini maka, tokoh semacam, Jamaluddin al Afghani (w. 1897M), Muhammad Abduh (w. 1905M), Rasyid Rida (w.1935M), Ahmad Khan (w.1898M) menyeru pentingnya umat Islam belajar dari Barat dalam hal sains dan teknologi (H. F. Zarkasyi et al., 2016). Perkembangan sains dan teknologi bukan tanpa 
masalah. Banyak penelitian yang mendalam mengenai dampak jangka panjang dari pesatnya perkembangan sains tersebut. Matthew Orr (2006) memberikan sebuah ilustrasi dari penelitian mengenai pengaruh aspek manusia dalam problem perubahan iklim dunia. Selain itu sebagaimana al Attas katakan bahwa sains modern khususnya sains sosial sebagai hasil dari program filsafat membawa watak, kepribadian dan ideologi sekulerisme; karena sains merupakan hasil kerja dari prisma pandangan hidup suatu bangsa (Syed Muhamed Naquib Al-Attas, 1993). Artinya al Attas melihat bahwa dalam sains modern terdapat watak sekularisme yang beretentangan dengan cara pandang Islam. Oleh karena itu akan diuraikan respon ilmuwan Muslim terhadap dominasi sains modern tersebut.

\section{Respon Ilmuwan Muslim terhadap Sains Modern}

Hegemoni ilmu pengetahuan Barat modern ke dunia Islam sejatinya menjadi dilema kaum muslimin (Syed M Naquib Al-Attas, 2001). Ilmu pengetahuan modern yang memiliki watak, kepribadian dan esensi sekuler, memilik banyak ketidakcocokan dengan nilai, watak, kepribadian tujuan dan cara hidup dalam Islam (Daud, 1998). Oleh karenanya, para ilmuwan Muslim berupaya merespon hegemoni sains modern tersebut. Seperti yang dilakukan oleh Syed Muhammad Naquib alAttas, Ziauddin Sardar, Isma'il Raji al-Faruqi, Sayyed Hossein Nasr, Maurice Bucaille dan sebaginya. Para ilmuwan Muslim tersebut melakukan kajian kritis terhadap ilmu pengetahuan (sains) sekuler yang sudah menjadi penyakit akut dikalangan para saintis. Banyak pendekatan dan ide-ide baru yang dirumuskan dalam mendefinisikan sains sebagai sebuah disiplin ilmu yang memberikan manfaat kepada kesejahteraan manusia.
Usaha tersebut berhasil mengetengahkan wacana 'Islamisasi sains modern'. Dalam istilah Wahyudin Darmalaksana (2020) disebut teologi sains. Sebuah langkah taktis yang mesti dilakukan dalam membangkitkan kembali sains Islam. Salah satu pendekatan terpenting dalam wacana Islamisasi Ilmu adalah dengan melakukan pendekatan praktis. Menurut eksponen pendekatan ini, sains Islam, tidak cukup hanya diwacanakan, tetapi harus diwujudkan dalam praktik penelitian. Sains Islam itu mengajarkan hidup sesuai dengan nilai-nilai Islam (Subky, 2013). Kalau berupa ilmu alam atau natural science, maka bagaimana seorang ilmuwan muslim melakukan penelitian saintifik yang tidak merusak alam, yang ramah lingkungan, yang menghormati lagi memelihara keanekaragaman hayati. Kalau berupa sains sosial harus berorientasi pada kemaslahatan kehidupan manusia. Pendekatan ini yang dikedepankan oleh Adi Setia dari Malaysia dan Nadia Lawton dari Australia (Akbar, 2016).

Pendekatan ini sebenarnya memberikan akses praktis secara langsung dan bisa dilihat hasilnya. Ilmuwan Muslim mengarahkan penelitiannya, dan kerja ilmiahnya itu untuk memenuhi kemaslahatan umat Islam khususnya dan umat manusia umumnya. Orientasi yang harus dimiliki seorang ilmuwan muslim adalah menghasilkan produk-produk sains yang berbasis pada visi Islam. Guna menuju hasil yang diinginkan dibutuhkan berbagai model-model penelitian sains Islam; yang perlu dikembangkan oleh komunitas ilmuwan Muslim.

\section{Upaya Baru Penelitian Sains Islam}

Secara praktis, sains Islam dapat digolongkan ke dalam 3 model bentuk penelitian. Yakni penelitian sejarah sains, penelitian filsafat sains dan program riset (Setia, 2007). 
Pertama, penelitian sejarah sains. Penelitian model ini berbicara tentang sains dari sisi sejarah. Tujuan dari pendekatan ini adalah menghadirkan kembali temuan-temuan sains di masa lalu (H. F. Zarkasyi et al., 2016). Penelitian bisa dilakukan dengan menganalisa manuskrip dari seorang ilmuwan baik Barat maupun Islam dengan cara membandingkan dan melakukan penelusuran secara kronologis. Penelitian ini akan berguna mengungkap konsep-konsep penting ilmuwan terdahulu guna pengembangan sains Islam kedepannya.

Kedua, Sains sebagai disiplin ilmu dalam bidang filsafat sains. Sebagaimana disinggung di awal, dalam peradaban Barat modern dikenal tokoh tokoh filosof semacam Rene Descrates, Spinoza, Auguste Comte, Immanuel Kant dll, yang berhasil meletakkan filsafat sains yang menjadi dasar pengembangan sains di dunia Barat. Di dunia Islam saat ini ada, Naquib al Attas, Syed Hossein Nasr, Ismail Raji al Faruqi dan banyak lagi yang berfokus pada meletakkan filsafat sains Islam (H. F. Zarkasyi et al., 2016); yang berguna sebagai asas perwujudan sains Islam yang hakiki.

Ketiga, sains sebagai program riset. Program ini berisi penelitian (research program) jangka panjang yang bersifat tajribi (experimental) amali (practical) dan indrawi (empirical) (Setia, 2010; H. F. Zarkasyi et al., 2016). Model ketiga ini idealnya berporos pada penelitian model pertama dan kedua, sehingga mampu menghasilkan produk sains yang baru yang dibutuhkan masyarakat saat ini.

Jika menilik sains Barat saat ini, program penelitian (research programe) -yang berporos pada filsafat materialistik- bukanlah barang yang langka. Bahkan program riset telah menjadi tulang punggung untuk mencapai kemajuan yang pesat khususnya dalam sains dan teknologi; meskipun yang dihasilkan adalah sains sekuler.
Hal sebaliknya pada dunia Islam, sains Islam dapat dikatakan masih tertinggal, khususnya pada sisi program riset. Hal ini mengakibatkan kebekuan peradaban Islam dalam sains dan teknologi. Inilah yang menyebabkan dunia Islam tertinggal bahkan dihegemoni oleh sains Barat modern. Bukti nyata Islamisasi sains sebenarnya sudah terwujud hanya saja baru terjadi pada model penelitian pertama dan kedua. Penelitian sains Islam dengan pendekatan sejarah telah dilakukan misalnya oleh A.I Sabra, The Optics of Ibn Haytham, Medieval Agriculture and Islamic Science: The Almanac of a Yemeni Sultan oleh Martin Varisco dan Donald R Hill, Islamic Science and Engineering (H. F. Zarkasyi et al., 2016). Penelitian sains pada mode kedua yakni menggunakan pendekatan Filsafat juga telah ada. sebagai contoh Islam and the Philosophy of Science karya al Attas, Classification of Knowledge in Islam dan The History dan Philosophy of Science oleh Osman Bakar, The Philosophy of the Kalam oleh Harry A Wolfson (H. F. Zarkasyi et al., 2016). Sedangkan penelitian sains Islam pada makna ketiga masih tertinggal dari keduanya. Oleh karena itu, wacana Islamisasi sains hendaknya juga difokuskan ke dalam sebuah program riset yang nyata dan berkelanjutan.

\section{Kesimpulan}

Penelitian ini menyimpulkan bahwa 1) sejarah sains Islam dibangun berdasarkan wahyu yang dikonfirmasi dengan akal dan observasi, sementara dalam sejarah lahirnya sains modern berpaku pada gerakan sekularisasi; penolakan atas doktrin agama (Gereja); 2) Setelah sains Islam mengalami kemunduran akibat dari berbagaimacam hal, sains moderlah yang menjadi kiblat sains dunia; dan 3) Respon ilmuwan Muslim terhadap dominasi sains modern adalah dengan gerakan Islamisasi ilmu pengetahuan. 
Meskipun sains Islam -dalam wacana Islamisasi- memiliki pijakan filosofis yang begitu kuat namun sains Islam masih tertinggal pada makna sebagai sebuah program riset. Hal ini tercermin dari tertinggalnya umat Islam dalam kemajuan teknologi; dimana program riset menjadi tumpuannya. Oleh karena itu, sains Islam hendaknya dapat diaktualkan ke dalam sebuah program riset yang berkelanjutan, sebagaimana dicapai kaum Muslimin terdahulu pada masa kejayaannya.

\section{Daftar Pustaka}

Abattouy, M., Ali, P. W., Ayduz, S., Al Azzawi, S., Burnett, C., Gani, M., Ghazanfar, S. M., Al Hassani, S. T. S., Idrisi, Z., Ihsanoglu, E., Kaadan, A. N., Al Rawi, M., Saoud, R., Sari, N., Sayili, A., Shaikh, I., Tekeli, S., Winterburn, E., \& Zaimeceh, S. (2005). 1001Inventions: Muslim Heritage in Our World (pp. 1-366). The Foundation for Science, Technology and Civilization FSTC.

Acikgenc, A. (1996). Islamic Science toward a Definition. ISTAC.

Akbar, C. (2016). Empat Pendekatan Sains Islam. Hidayatullah.Com.

Akhyar, M. (2017). Polemik Negara Islam atau Islam Bernegara. Program Kaderisasi Ulama UNIDA Gontor.

Al-Attas, Syed M Naquib. (2001). Risalah untuk Kaum Muslimin. ISTAC.

Al-Attas, Syed Muhamed Naquib. (1993). Islam-and-Secularism-Attas.Pdf.

Al-Attas, Syed Muhamed Naquib. (1995). Islam dan Filsafat Sains. Mizan.

Al-Faruqi, I. R.

(1980). English_Al_Tawhid_Its_Implication_for Thought_and_Life.pdf (2nd ed.). The International Institute of Islamic Thought (IIIT).

Al-Kathany, A. (1995). The Universality of Islam. Dar-al Moayyad.

Aprison, W. (2015). Mendamaikan Sains dan Agama: Mempertimbangkan Teori Harun Nasution. Jurnal Pendidikan Islam, 4(2), 241-259.
Arifin, Z. (2008). Model-Model Relasi Agama Dan Sains. Psikoislamika: Jurnal Psikologi Dan Psikologi Islam, 5(2). https://doi.org/10.18860/psi.v0i0.353

Asy'ari, H. (2018). Renaisans Eropa dan Transmisi Keilmuan Islam ke Eropa. JUSPI: Jurnal Sejarah Peradaban Islam, vol.2(no.1), 1-14.

Attar, M. F. (2015). Fondasi Realisme Ibn Sīnā dalam Metafisika Kitāb al - Syifā , Pendahuluan dalam alam pikiran kita . Hal ini sesuai dengan itu disebut dalam berbagai konteks : tradisional bahwa suatu benda dapat atau apakah manusia itu banyak? Jika dia satu. Ilmu Ushuluddin, 2(3), 185-200.

Azizah, N. (2018). Hubungan Ilmu dan Agama dalam Prespektif Islam Telaah Pemikiran Kuntowijoyo. Prosiding Konferensi Integrasi Interkoneksi Islam Dan Sains, 1(September), 151-156.

Bammate, H. (1962). Muslim Contribution to Civilization. American Trust Publication.

Barbour, I. G. (2000). When Science Meets Religion,. Harper Collins Publisher.

Barbour, I. G. (2002). Nature Human Nature and God. Fortress Press.

Cambridge University. (2008). Cambridge Advanced learner's Dictionary (3rd Editio). Cambridge University Press.

Crowther, J. (2010). Oxford Advanced Learner's Dictionary (J. Crowther (ed.)). Oxford University Press, ,.

Darmalaksana, W., \& Busro, B. (2020). Teologi Sains: Refleksi Implementasi Integrasi Ilmu di Indonesia. Intizar, 26(2), 55-64. https://doi.org/10.19109/intizar.v26i2.785 5

Daud, W. M. N. W. (1998). The Educational Philosophy and Pracice of Syed Muhammad Naquib al-Attas. ISTAC.

Drapper, J. W. (1875). Histort of The Conflict Between Religion and Science. Cambridge University Press.

Fahmy Zarkasyi, H. (2015). Tamaddun sebagai konsep peradaban Islam. Tsaqafah, 11(1), $1-28$.

Gunawan, S. (2019). PERANAN ISLAM DALAM PEMBANGUNAN PRADABAN DUNIA. Jurnal El-Qanuny, 
$5,45-62$.

Hadi, F. S. (2019). Tawhid sebagai Prinsip Primordial Peradaban Islam: Studi Pemikiran Isma'il Raji al-Faruqi. Tsaqafah, 15(2), 265. https://doi.org/10.21111/tsaqafah.v15i2.32 89

Hadi, S., \& Ashari, A. (2020). Mendudukkan Kembali Makna Ilmu dan Sains dalam Islam. Tasfiyah, 4(1), 91. https://doi.org/10.21111/tasfiyah.v4i1.396 3

Hidayatullah, S. (2019). Agama dan Sains: Sebuah Kajian Tentang Relasi dan Metodologi. Jurnal Filsafat, 29(1), 102133. https://doi.org/10.22146/jf.30246

Hoesin, O. A. (1964). Kultur Islam. Bulan Bintang.

Husaini, A., Arif, S., Syafrin, N., Alim, A., Karnia, Dinar, D., Armas, A., Syarif, N., \& Handrianto, B. (2013). Filsasat Ilmu Perspektif Barat dan Islam. Gema Insani Press.

Ilafi, A. (2021a). 5 Ilmuwan Muslim di Bidang Kedokteran yang Karyanya Paling Berpengaruh. Www.Idntimes.Com.

Ilafi, A. (2021b). 5 Ilmuwan Muslim Paling Berpengaruh di Bidang Astronomi, Tokoh Hebat! Www.Idntimes.Com.

Ismail, F. (1997). Paradigma Kebudayaan Islam. Titian Ilahi Press.

Jessie, S. (2016). The Renaissance: The "Rebirth" of Science \& Culture. Www.Livescience.Com.

Khakim, U., Amrullah, K., \& Nasif, H. (2021). METODE SAINS : MEMBACA PEMIKIRAN EPISTEMOLOGIS AL ATTAS DAN WALL. Indonesian Journal of Islamic Study, 2(02), 181-190.

Khakim, U., Kurniyanto, T., Ramadhan, M. U. C., Habiburrahman, M., \& Rahmadian, M. I. (2020). God and Worldview according to al-Attas and Wall. Tsaqafah, 16(2), 223244.

https://doi.org/10.21111/tsaqafah.v16i2.48 53

Khan, M. A. R. (1973). Muslim Contribution Science and Culture Lahore. Sh. Muhammad Ashraf.

Khuluq, V. H., \& Syamsuri, S. (2020). Perkembangan Pertanian Dalam Peradaban
Islam: Sebuah Telaah Historis Kitab Al Filaha Ibnu Awwam. Jurnal Tamaddun: Jurnal Sejarah Dan Kebudayaan Islam, $8(1)$.

https://doi.org/10.24235/tamaddun.v8i1.60 76

Krippendoff, K. H. (2004). Content Analysis An Introduction to Its Metodology (2nd Editio). Sage Peblication.

Ma'afi, R. H., \& Cholidi, M. F. (2019). Seyyedhossein Nasr on Islam and Science. JURNAL YAQZHAN: Analisis Filsafat, Agama Dan Kemanusiaan, 5(1), 152. https://doi.org/10.24235/jy.v5i1.4522

Manzur, I. (n.d.). Lisân al'Arab (jilid 13,). Dâr Sâdir.

Mas'udi. (2013). Menyingkap Hubungan agaMa Dan FilsaFat: Merenda kesesatan Filsafat al-ghazali, Merespons keterhubungan Filsafat dan agama ibnu Rusyd. Jurnal Penelitian, 7(2), 301-322.

Muslih, M. (2016). Filsafat Ilmu: Kajian atas Asumsi Dasar Paradigma dan Kerangka Keilmuan. Belukar.

Muslih, M. (2017). Falsafah Sains, dari Isu Integrasi Keilmuan Menuju Lahirnya Sains Teistik. LESFI.

Muslih, M. K. (2018). Worldview Islam: Pembahasan tentang Konsep-Konsep Penting dalam Islam. Pusat Islamisasi Ilmu(PII) dan Unida Gontor Press.

National Commission for UNESCO. (1977). Islamic and arab Contribution to the European Renaissance.

Nordin, S. (2000). Sain Menurut Perspektif Islam, . Dwi Rama.

Nugraha, M. T. (2020). Integrasi Ilmu dan Agama: Praktik Islamisasi Ilmu Pengetahuan Umum di Perguruan Tinggi. Al-Hikmah: Jurnal Agama Dan Ilmu Pengetahuan, 17(1), 29-37.

Nugroho, A. F. (2018). Krisis Sains Modern Krisis Dunia Modern Dan Problem Keilmuan. Jurnal Penelitian Agama, 19(2), 80-95.

https://doi.org/10.24090/jpa.v19i2.2018.pp 80-95

Orr, M. (2006). 'What is a scientific world view, and how does it bear on the interplay of science and religion?', Zygon. https://doi.org/doi: $\quad 10.1111 /$ j.1467- 
9744.2005.00748.x.

Qardawi, Y. (1997). As-sunnatû Mashdaran lil Ma'rifati wal Hadhârati, . Dârusy Syuruq.

Salafuddin. (2013). Islamisasi Ilmu Pengetahuan. Forum Tarbiyah, 11(2).

Setia, A. (2007). Three Meaning of Islamic Science. Islam and Science, 5(1).

Setia, A. (2010). Dewesternizing \& Islamizing the Sciences: Neo-ghazalian, Operationalizing Vision, Attasian. HAKIM, $1-30$.

Sholeh, S. (2017). Islamisasi Ilmu Pengetahuan (Konsep Pemikiran Ismail Raji Al-Faruqi dan Syed Muhammad Naquib Al-Attas). Al-Hikmah: Jurnal Agama Dan Ilmu Pengetahuan, 14(2), 209-221. https://doi.org/10.25299/alhikmah:jaip.2017.vol14(2).1029

Siregar, I. S., \& Siregar, L. M. (2018). Studi Komparatif Pemikiran Ismail Raji AlFaruqi Dan Syed Muhammad Naquib AlAttas. Al-Hikmah: Jurnal Agama Dan Ilmu Pengetahuan, 15(1), 85-98. https://doi.org/10.25299/jaip.2018.vol15(1 ). 1588

Sitorus, F. K. (2016). Kant:Dari Subjek yang Kosong Hingga Tuhan sebagai Postulat. Serambi Salihara.

Subky, B. (2013). Islamisasi Ilmu Pengetahuan. Edukasia Islamika, 11(2), 64-74.

Sugiyono. (2011). Metode Penelitian Kuantitatif, Kualitatif dan $R \& D$. Alfabetha.

Suriasumantri, J. S. (2007). Filsafat Ilmu: Sebuah Pengantar Populer. Pustaka Sinar Harapan.

Sutoyo. (2010). Religiusitas Sains, Meretas Jalan Menuju Peradaban Zaman (Diskursus Filsafat Ilmu). UB Press.

Taqiyuddin, M. (2021). Hubungan Islam dan Sains: Tawaran Syed Muhammad Naquib Al-Attas. Islamadina: Jurnal Pemikiran Islam, 22(1), 81. https://doi.org/10.30595/islamadina.v22i1. 7216

Tasrif, M. (2008). Telaah Pemikiran Kuntowijoyo tentang Relasi lslam. Dialogia, $6(2)$.

Tavakoli, H. (2012). A Dictionary of Research Methodology and Statistic in Aplied Linguistic,. Rahma Press.
Team, O. (1975). Encyclopedia of World Religions: Judaism, Christianity, Islam, Buddhism, Zen, Hinduism, Prehistoric \&Primitive Religions,. Octopus Books Limited,.

Wahyuni, F. (2018). Islamisasi Ilmu Pengetahuan ( Upaya Mengurai Dikotomi Ilmu Pengetahuan dalam Islam ). Qalamuna, 10(2), 1-12.

Zaprulkhan, Z. (2017). Membangun Relasi Agama Dan Ilmu Pengetahuan. Kalam, $7(2)$, 259. https://doi.org/10.24042/klm.v7i2.465

Zarkasyi, H. F. (2015). Peradaban Islam, Makna dan Strategi Pembangunnya. CIOS.

Zarkasyi, H. F., Arif, S., \& Handrianto, B. (2016). Islamic Sciences, Paradigma, Fakta dan Agenda, (S. Arif (ed.)). INSIST. Zarkasyi, I. (1986). Ushuluddin. Trimurti Press. 